\title{
Notícia: Ao Mestre Luiz Otávio de Seixas Queiroz, Com Carinho
}

\author{
Cecilia Guarnieri Batista ${ }^{1}$ e Elenice A. de Moraes Ferrari \\ Universidade Estudual de Campinas \\ Diana Tosello Laloni \\ Pontifícia Universidade Católica de Campinas
}

\section{News: For Professor Luiz Otavio de Seixas Queiroz, Affectionately}

Faleceu em Campinas, no dia 17 de junho de 2003, aos 65 anos, o Prof. Dr. Luiz Otávio de Seixas Queiroz. Nascido em Campinas, foi aluno da $2^{\mathrm{a}}$ turma do curso de psicologia da Universidade de São Paulo (USP), no final dos anos 50. Ainda antes de terminar a graduação, foi convidado pela professora doutora Carolina Bori para trabalhar na então nascente Universidade de Brasília (UnB). Participou da proposta de criação da nova universidade, atuando de forma inovadora em ensino e pesquisa. Foi monitor do primeiro Curso de Ensino Programado Individualizado, elaborado na UnB pelos professores Carolina Bori, Fred Keller, Gilmour Sherman e Rodolfo Azzi. Foi membro ativo dos movimentos sócio-políticos que marcaram a história da $\mathrm{UnB}$ naquela época e fez parte do grupo de professores demitidos dessa universidade em 1964.

Retornando a São Paulo, foi docente do curso de Pedagogia da Faculdade de Filosofia, Ciências e Letras de Rio Claro (atual Universidade Estadual Paulista - Unesp) onde, pela competência e enorme entusiasmo didático e científico que lhe eram característicos, teve uma participação influente na formação de alunos interessados na análise experimental do comportamento.

Em 1966, foi admitido como professor da então Universidade Católica de Campinas (UCC), que iniciara seu curso de Psicologia em 1965. Teve atuação destacada nessa universidade. Na qualidade de diretor do Instituto de Psicologia, promoveu a estruturação do curso e da clínica de Psicologia, dando-lhe feição moderna, científica e que contemplava as diferentes correntes de pensamento em Psicologia. Procurou fortalecer a estrutura departamental e trazer nomes representativos das várias abordagens em psicologia, a maioria vinda de São Paulo a seu convite.

Ministrou as disciplinas de Psicologia Experimental I, II e III, tendo sido o responsável pela montagem do Laboratório de Condicionamento Operante. No conjunto, essas disciplinas incluíam estudos de comportamento animal e humano, encerrando com as aplicações para situações clínicas. Criou, ainda, a supervisão de estágio em Modificação de Comportamento, ministrando essa disciplina para os alunos do $5^{\circ}$ ano de psicologia, sendo um dos pioneiros na formação do Terapeuta Comportamental nos cursos de psicologia no Brasil.

Participou, com outros professores da então Faculdade de Filosofia, Ciências e Letras da UCC, do movimento pela

1 Endereço: Cepre - Centro de Estudos e Pesquisas em Reabilitação "Prof. Dr. Gabriel O.S. Porto" FCM - Universidade Estadual de Campinas. Rua Tessália Vieira de Camargo, 126. CP: 6111. Bairro Barão Geraldo. CEP: 13.084-971 - Campinas-SP. E-mail: cecigb@fcm.unicamp.br reestruturação pedagógica dessa Faculdade. Teve sempre um papel ativo, de liderança, trazendo movimento, vida e modernidade às estruturas universitárias em que se engajava. Muitos dos alunos da UCC daquele período, inspirados por Luiz Otávio, buscaram os recém-criados cursos de pós-graduação em Psicologia, para seguir carreira como docentes e pesquisadores.

Em 1969, durante a vigência do AI-5, a reitoria decidiu anexar o Instituto de Psicologia à Faculdade de Filosofia, Ciências e Letras. Um movimento de protesto de professores e alunos, que durou semanas, levou ao pedido de demissão coletiva da quase totalidade dos professores do curso de psicologia e de muitos professores da Faculdade de Filosofia, Ciências e Letras, num total de 49 professores.

A partir dessa época, Luiz Otávio passou a atuar principalmente em clínica particular, tornando-se altamente conceituado como terapeuta de adultos. Ao lado dessa atividade, desenvolveu, no início dos anos 70, um trabalho pioneiro em uma enfermaria de pacientes crônicos, a maioria com muitos anos de internação, no Instituto Bairral de Psiquiatria, Itapira. Com uma equipe de psicólogos e estagiários, adaptou para a realidade brasileira um sistema de economia de fichas (token economy), fundamentado em recém publicados trabalhos norte-americanos. Os resultados obtidos incluíram a participação de pacientes, usualmente apáticos, em várias atividades de trabalho, auto-cuidados e lazer. O relato parcial dessas atividades resultou em sua tese de doutorado, defendida em 1973 no Instituto de Psicologia da USP.

Luiz Otávio teve mais uma breve experiência docente, ao participar da elaboração das disciplinas da área da Terapia Comportamental do curso de graduação da PUC-SP, no início da década de 70 .

Foi presidente do Conselho Regional de Psicologia de São Paulo entre 1980 e 1982, propondo a discussão do papel dos Conselhos Profissionais, centrado no incentivo à formação do psicólogo, ao invés do enfoque na aplicação de sanções.

Luiz Otávio não foi apenas um professor, mas um mestre. Era notável a sua habilidade no estabelecimento de condições motivadoras e de reforço na busca de conhecimento e aquisição de repertórios eficazes para a análise do comportamento. Estabeleceu os fundamentos da formação de várias gerações de estudiosos do comportamento. A convivência com ele não resultava apenas em aprendizagem de princípios e conceitos comportamentais, mas também na reflexão sobre as implicações desses princípios na vida pessoal, na sociedade e nos conflitos sociais, políticos e culturais que explodiram nos anos sessenta. Era uma época de transformação social mundial e ele sabia conduzir, como poucos, a análise crítica 
das implicações da mudança dos valores e das regras nas ações humanas. Ele questionava e levava ao questionamento. A sua influência deverá se manter viva ainda por muito tempo. É lamentável que, devido à história de repressão nos anos 60 , a universidade brasileira tenha perdido o trabalho desse mestre e, dessa forma, tantas gerações tenham sido privadas da sua influente ação na formação acadêmica.
Sem dúvida, Luiz Otávio foi sempre um exemplo de liderança, especialmente de fomento a ações coletivas ligadas à renovação de estruturas. Destacou-se por uma postura de busca de ações cooperativas, com perfil de aceitação e de convivência na diferença. A oportunidade de estudar com ele foi um prazer e um privilégio. 